\title{
Development and Application of Exceedance Model for Surface Water Quality Parameters
}

\author{
Tahir Ali Akbar ${ }^{1 *}$, Gopal Achari², Quazi K. Hassan³, Qaisar Mahmood \\ 'Department of Civil Engineering, COMSATS University Islamabad, Abbottabad Campus, \\ Abbottabad 22060, KPK, Pakistan \\ ${ }^{2}$ Department of Civil Engineering, Schulich School of Engineering, University of Calgary, \\ 2500 University Dr NW, Calgary, Alberta T2N 1N4 Canada \\ ${ }^{3}$ Department of Geomatics Engineering, Schulich School of Engineering, University of Calgary; \\ 2500 University NW, Calgary, Alberta T2N 1N4 Canada \\ ${ }^{4}$ Department of Environmental Sciences, COMSATS University Islamabad, Abbottabad Campus, \\ Abbottabad 22060, KPK, Pakistan
}

Received: 25 February 2020

Accepted: 17 June 2020

\begin{abstract}
Surface water quality is continuously changing due to anthropogenic activities and natural causes. The drinking water treatment technology can be expensive and ineffective if implemented without identifying the patterns of parameter exceedances. The objectives of this paper were to: (i) develop a mean exceedance model; (ii) apply the model for identification of the exceeded parameters; (iii) obtain the exceedance patterns of parameters; and (iv) obtain decision making on the treatment of parameters. The mean exceedance model was developed by utilizing cluster database of 12 major Canadian rivers. The clusters were developed on the basis of normalization model, principal component analysis, total exceedance model and Canadian Water Quality Index. On application of mean exceedance model, the parameters were identified, which exceeded the water quality guidelines. The output of mean exceedance model was utilized for making decision on treatment of parameters. The normalized water quality data of 17 parameters was used to develop a mean exceedance model to obtain exceedance level for water quality parameters. The mean exceedance for the parameters increased as the cluster number increased from low to high for all the rivers. Overall, the mean exceedance was higher for fecal coliforms, turbidity, total phosphorus, total nitrogen, true colour, dissolved oxygen, iron and manganese. The exceedance in fecal coliforms, turbidity, total phosphorus, total nitrogen, true colour, dissolved oxygen could be related to anthropogenic activities of landuse/landcover (LULC). The exceedance in iron and manganese could be associated to natural mineralization. The mean exceedance model was found useful for obtaining the specific parameters with their exceedance levels. The parameter exceedance patterns
\end{abstract}

*e-mail: drtahir@cuiatd.edu.pk 
could be utilized for the development of economical, efficient and targeted treatment technology for the source waters.

Keywords: Alberta Rivers, water quality modelling, parameter exceedance, drinking water treatment, water treatment technologies

\section{Introduction}

Surface water pollution is a prime threat to the sustainability of surface waters in various parts of the world including Canada [1]. The main source of drinking water is surface water of Albertans in Canada [2]. Approximately $97.5 \%$ of consumptive use of water, which serves small and large communities in Alberta, comes from surface water. The origins of Alberta's major rivers are glaciers and snow packs of Rocky Mountains. The surface water quality of rivers changes as water flows through different types of Landuse/ Landcover (LULC) [3, 4]. The water deterioration occurs due to anthropogenic activities (e.g., agriculture, forests, industrial, residential etc.) and natural factors (i.e., geology, soil, climate, precipitation etc.). The climatic changes can degrade the water quality [5-7]. The temperature variations due to seasonal changes also affect the surface water quality in Alberta.

In order to monitor the water quality, the water quality indices are used. The water quality index is a mechanism built on numerical expression for describing the quality level of water [8]. A study was conducted in which the water quality index was created using ten parameters, which were dissolved oxygen, $\mathrm{pH}$, coliforms, specific conductance, alkalinity, and chloride. The index score was attained with a linear sum aggregation [9]. In another study, a multiplicative water quality index was developed by assigning weights to every parameter subjectively. The weight-based index was found useful and had significant impact on the indices [10]. Some other studies also included weight-based patterns in their indices [11]. In another study, an index was developed based on empirical data for recreation water and sensitivity functions were used to allot a numerical value between 0 and 1 . The sensitivity functions were represented using the negative exponential curves. Sub-indices were defined and combined to obtain the geometric mean [12].

For monitoring the quality of major rivers of Alberta, Long-Term River Network (LTRN) program and the Canadian Water Quality Index (CWQI) are used. In LTRN program, the water samples are collected from fixed sampling sites and are tested for several parameters every month. To check the suitability of water for explicit uses, the water quality is assessed using Canadian water quality guidelines. The quality is considered acceptable when these values are found within the limits [2]. However, it was important to create a model that could classify the surface water quality of Alberta's major rivers to identify the particular parameters deteriorating the water quality and guide in "treatment decision making" based on the outputs of the model. For this purpose, 12 major rivers of Alberta were classified and analyzed using principal component analysis (PCA) and clustering techniques by Akbar et al. [13]. The normalization models were developed on the basis of Canadian drinking water quality guidelines. The measured parameters were compared with the Canadian drinking water quality guidelines to develop a normalization model. The model was used to normalize the data of all 17 parameters. The normalized data of 17 parameters for 23 sampling sites during 2004-2008 were used for PCA to identify Principal Components (PCs) and obtain the dominant parameters. The dominant parameters obtained from PCs were dissolved solids, true color, $\mathrm{pH}$, iron, fecal coliform, dissolved oxygen, and turbidity. The data for dominant parameters was used to develop the total exceedance model. The model was applied to generate five clusters. In evaluation, the clusters showed strong relationship with the classes of Canadian Water Quality Index (CWQI). Higher cluster numbers (i.e., 4, and 5) were observed in growing season whereas lower cluster numbers (i.e., 1, 2, 3) were found during winter. The agriculture could be responsible for deteriorating water quality in growing season [13].

The clusters of Alberta surface waters could be used to develop economical, efficient and targeted treatment technologies. Normally the water treatment technology is implemented with all built-in treatment processes. It makes the treatment costly, ineffective and untargeted. It is quite possible that in some places, advanced level of treatment might not be necessary as the water quality is intrinsically good. Different treatment technologies target different pollutants. For example in-line filtration is useful for water having low turbidity, direct filtration is beneficial for low to moderate turbidity and conventional treatment is good for high turbidity [14]. Different membrane filtration technologies can be used for treating different pollutants e.g., (i) nano filtration can be used for removal of calcium and magnesium ions; (ii) ultrafiltration can be used for removal of calcium and magnesium ions; and (iii) microfiltration can be used for removing pathogens $[15,16]$. Different types of disinfectants (e.g., chlorine, chloramine, UV light, ozone, and chlorine dioxide) are used for controlling bacteria, virus and other organisms [17, 18]. It is quite possible that the source waters change with the time of the year. There may be periods when they have high turbidity and consequently require treatment for it while at other times of the year the turbidity is low enough that a high level of coagulant dosage is not warranted. 


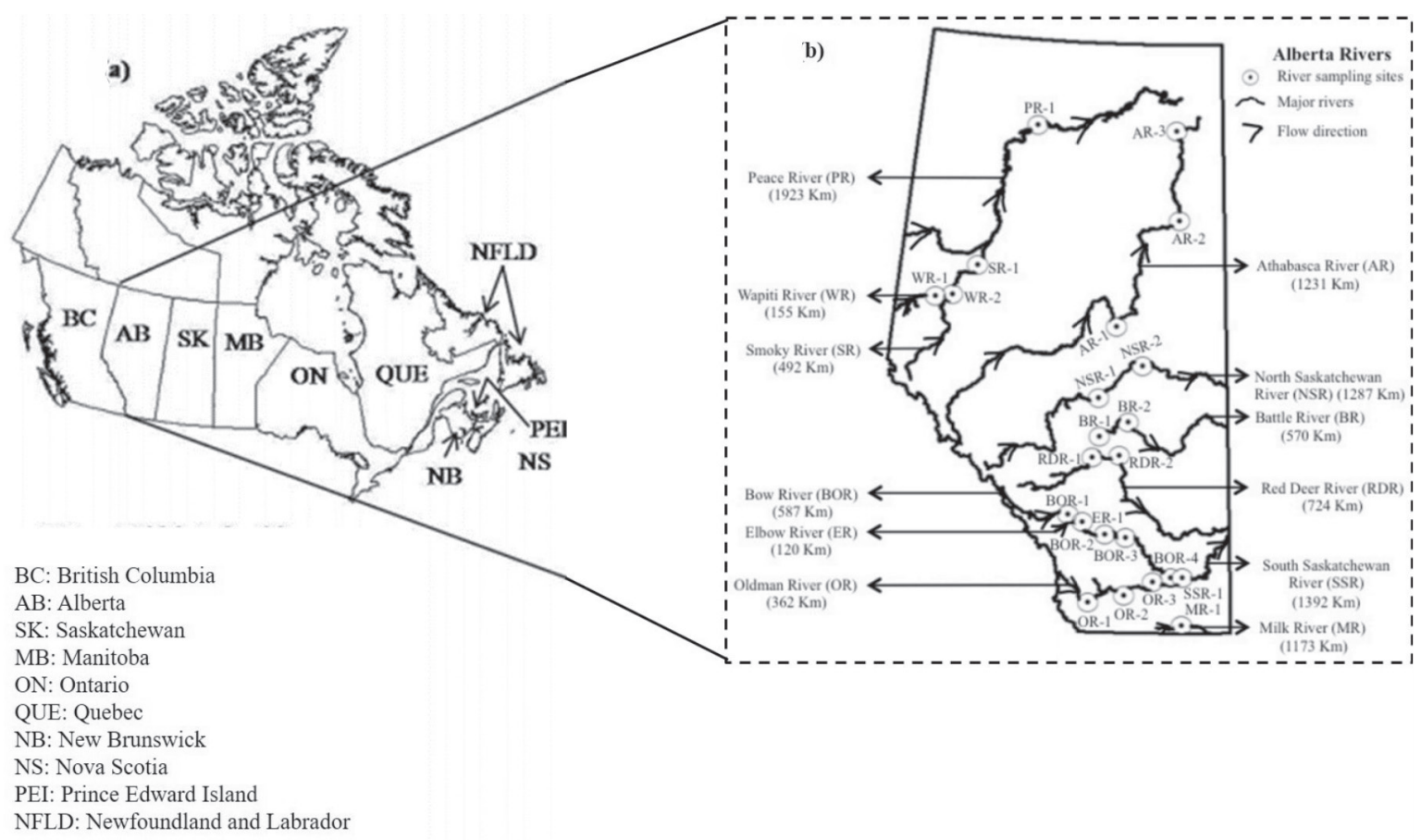

Fig. 1. a) Location of Alberta in Canada and b) Location of 23 sampling sites across the twelve major rivers in Alberta as published in Akbar et al. 2013 [13].

It is important to target the pollutants that are endemic to a particular area and accordingly devise a suitable treatment technology. The objectives of this paper were to: (i) develop the mean exceedance model using all 17 parameters; (ii) identify the parameters which exceeded the Canadian drinking water quality guidelines; (iii) obtain the exceedance patterns of parameters in clusters of 12 major rivers of Alberta during the period of five years (i.e., 2004-2008); and (iv) obtain decision on treatment of parameters.

\section{Materials and Methods}

\section{Study Area and Data Requirements}

The study area has 12 major rivers of Alberta as shown in Fig. 1. The lengths of rivers range from $120 \mathrm{~km}$ to $1923 \mathrm{~km}$ as presented in Fig. 1. Alberta is a western province of Canada where the average annual temperature in winter ranges from $-25.1^{\circ} \mathrm{C}$ to $-9.6^{\circ} \mathrm{C}$ and in summer it varies from $8.7^{\circ} \mathrm{C}$ to $18.5^{\circ} \mathrm{C}$ [19]. The major LULC types are needle leaf forests (57.57\%), grasses/cereal crops (30.11\%) and broad leaf forests $(5.25 \%)$ [20]. The information on surface water quality data is given on this website (https:// www.alberta.ca/surface-water-quality-data.aspx). The surface water quality of all major rivers is monitored for the different parameters on the monthly basis as part of Alberta Environment and Parks' Long Term River Network (LTRN) project. This data is accessible to public and can be downloaded using this website
(http://environment.alberta.ca/apps/EdwReportViewer/ LongTermRiverNetwork.aspx).

There are 23 sampling sites of the rivers. For each sampling site, we obtained the monthly values of the 17 water quality parameters for the period 2004-2008 from Alberta Environment. These parameters included: chloride $(\mathrm{Cl})$, dissolved organic carbon (DOC), dissolved oxygen (DO), fecal coliforms (FC), fluoride (F), iron $(\mathrm{Fe})$, manganese $(\mathrm{Mn}), \mathrm{pH}$, sodium $(\mathrm{Na})$, sulfate $\left(\mathrm{SO}_{4}\right)$ total dissolved solids (TDS), total hardness (TH), total nitrogen (TN), total phosphorus (TP), true color (TC), turbidity (TUR) and water temperature (WT). The guideline values for each of these parameters are given in Table 1 [21-23].

\section{Methods}

The method consisted of two major parts, such as: (i) utilization of cluster database; and (ii) development and application of mean exceedance model.

\section{Utilization of Cluster Database}

We used the data of monthly clusters for all the twelve rivers of Alberta during 2004-2008 developed by Akbar et al. [13]. In that study, the clusters were developed based on steps, which are described briefly here. First step includes development of normalization model as given in Eq. (1) and Eq. (2).

(Parameter)normalization $=\left[\frac{(\text { Parameter }) \text { measured }}{(\text { Parameter }) \text { guideline }}\right]^{0.25}$ 
(Parameter)normalization $=\left[\frac{(\text { Parameter }) \text { guideline }}{(\text { Parameter }) \text { measured }}\right]^{0.25}$

The guideline for Canadian drinking water quality was 0 for $\mathrm{FC}$ as shown in Table 1, so the power of constant number 0.25 was used in the equations 1 and 2. Exponent 0.25 was used in order to reduce the spread (because of the large variations in their measured values) between the 17 parameters given in the Table 1. These normalized models were applied on the 15 parameters (WT, TUR, TC, DOC, TP, TN, TDS, $\mathrm{TH}, \mathrm{Cl}, \mathrm{SO}_{4}, \mathrm{pH}>8.5, \mathrm{Na}, \mathrm{F}, \mathrm{Mn}$ and Fe using Eq. (1), and 2 parameters ( $\mathrm{DO}$ and $\mathrm{pH}<6$ ) using equation (2) for obtaining normalized water quality data during 2004-2008.

Step 2 included the application of principal component analysis to identify principal components and to obtain the dominant parameters using the normalized data. On the basis of highest loading values dominant parameter was selected from each PC.

Step 3 included the development of total exceedance model i.e., Eq. (3) using normalized data of dominant parameters obtained using Eq. (1) \& Eq. (2) during the period 2004 to 2008 .

$($ Exceedance $)$ total $=\sum[($ Dominant parameter $)$ normalized -1$\left.)\right]$

Table 1. Guidelines for Canadian drinking water quality [21-23].

\begin{tabular}{|c|c|}
\hline Parameter & Non-compliance if guideline value: \\
\hline WT & $>15^{\circ} \mathrm{C}$ \\
\hline DO & $<6.5 \mathrm{mg} / \mathrm{LL}$ \\
\hline TUR & $>1 \mathrm{NTU}$ \\
\hline $\mathrm{TC}$ & $>15 \mathrm{Pt}$ Co units \\
\hline DOC & $>5 \mathrm{mg} / \mathrm{LL}$ \\
\hline TDS & $>500 \mathrm{mg} / \mathrm{Lmg} / \mathrm{L}$ \\
\hline ТP & $>0.05 \mathrm{mg} / \mathrm{Lmg} / \mathrm{L}$ \\
\hline $\mathrm{TN}$ & $>1 \mathrm{mg} / \mathrm{Lmg} / \mathrm{L}$ \\
\hline $\mathrm{pH}$ & $<6.5$ or $>8.5$ \\
\hline $\mathrm{TH}$ & $>500 \mathrm{mg} / \mathrm{L}$ \\
\hline $\mathrm{Cl}$ & $>250 \mathrm{mg} / \mathrm{L}$ \\
\hline $\mathrm{SO}_{4}$ & $>500 \mathrm{mg} / \mathrm{L}$ \\
\hline $\mathrm{Na}$ & $>200 \mathrm{mg} / \mathrm{L}$ \\
\hline $\mathrm{F}$ & $>1.5 \mathrm{mg} / \mathrm{L}$ \\
\hline $\mathrm{FC}$ & $>0$ \\
\hline $\mathrm{Mn}$ & $>0.05 \mathrm{mg} / \mathrm{L}$ \\
\hline $\mathrm{Fe}$ & $>0.3 \mathrm{mg} / \mathrm{L}$ \\
\hline
\end{tabular}

In step 4, the exceedance values obtained, were used to identify the patterns to develop clusters for the classification of surface water quality of the rivers. Step 5 included the evaluation of clusters on the basis of CWQI using Eq. (4) [13]. CWQI is a tool implemented by Canadian Council of Ministers of the Environment (CCME) to provide reports on water quality in Canada. For evaluation the percent cumulative agreements between the clusters and CWQI classes were calculated for all rivers during the period 2004 to 2008.

$$
\mathrm{CWQI}=100-\left[\frac{\sqrt{F 1^{2}+F 2^{2}+F 3^{2}}}{1.732}\right]
$$

...where $\mathrm{F}_{1}, \mathrm{~F}_{2}$, and $\mathrm{F}_{3}$ are scope, frequency and amplitude which could be calculated using equations as given in Table 2 [13].

\section{Development and Application of Mean Exceedance Model}

In this sub-section, the steps consisted of the: (i) normalization of measured water quality data during the period 2004-2008 for WT, TUR, TC, DOC, TP, TN, TDS, TH, Cl, $\mathrm{SO}_{4}, \mathrm{pH}>8.5, \mathrm{Na}, \mathrm{F}, \mathrm{Mn}$ and $\mathrm{Fe}$ using Eq. (1), and $\mathrm{DO}$ and $\mathrm{pH}<6.5$ using Eq. (2) as explained in "Utilization of Cluster Database"; (ii) The normalized parameter dataset was used to develop a mean exceedance model as given in Eq. (5).

$($ Mean Exceedance $)$ parameter $=$ Mean $[($ parameter $)$ normalized -1$]$

Table 2. Equations used for calculation of CWQI and identifying classes using the data of 23 sampling sites for 12 rivers during the period 2004-2008 [13].

\begin{tabular}{|c|}
\hline $\mathrm{F} 1$ (Scope) $=\left(\frac{\text { Number of failed variables }}{\text { Total number of variables }}\right) \times 100$ \\
\hline $\mathrm{F} 2$ (Frequency) $=\left(\frac{\text { Number of failed tests }}{\text { Total number of tests }}\right) \times 100$ \\
excursion $i=\left(\frac{\text { Objective } j}{\text { Failed test value } i}\right)-1$ \\
excursion $i=\left(\frac{\text { Failed test value } i}{\text { Objective } j}\right)-1$ \\
nse $=\left(\frac{\sum_{i=1}^{n} \text { excursion } i}{\text { number of tests }}\right)$ \\
\hline F3(amplitude) $=\left(\frac{\text { nse }}{0.01 \text { nse }+0.01}\right)$ \\
\hline
\end{tabular}

Note: nse: normalized sum of excursion 


\begin{tabular}{|c|c|c|c|c|c|c|c|c|c|c|c|c|}
\hline 号 & $\bar{\sigma}$ & $\begin{array}{l}\infty \\
\infty \\
0 \\
0\end{array}$ & 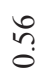 & $\stackrel{\text { fo }}{0}$ & i⿱ & $\begin{array}{l}\infty \\
\tilde{0} \\
0\end{array}$ & $\stackrel{q}{0}$ & $\stackrel{q}{\stackrel{q}{0}}$ & $\stackrel{g}{\circ}$ & $\begin{array}{l}8 \\
0 \\
0\end{array}$ & ț & : \\
\hline$\stackrel{05}{50}$ & $\overrightarrow{\widetilde{\sigma}}$ & $\frac{\infty}{0}$ & ô. & $\ddot{\circ}$ & $\begin{array}{l}8 \\
0\end{array}$ & $\overrightarrow{0}$ & $\overrightarrow{0}$ & $\begin{array}{l}\overrightarrow{0} \\
0 \\
0\end{array}$ & $\overrightarrow{0}$ & $\begin{array}{l}0 \\
0 \\
0\end{array}$ & $\stackrel{0}{0}$ & $\stackrel{t}{\circ}$ \\
\hline 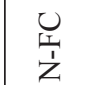 & $\stackrel{\infty}{\stackrel{\infty}{-}}$ & $\vec{n}$ & $\vec{\lambda}$ & 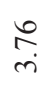 & $\stackrel{9}{=}$ & $\stackrel{\infty}{\stackrel{\infty}{-}}$ & $\underset{F}{\vec{F}}$ & \begin{tabular}{|l}
$\infty$ \\
$\stackrel{\infty}{-}$ \\
-
\end{tabular} & 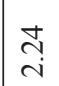 & $\stackrel{\infty}{\stackrel{\infty}{-}}$ & $\stackrel{\Re}{\sigma}$ & $\underset{\sim}{\tilde{\gamma}}$ \\
\hline$\underset{\Xi}{\breve{\Xi}}$ & 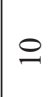 & f & $\underset{\sim}{\sim}$ & \&్లి & N & 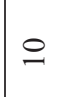 & $\nabla$ & 잉 & 2 & 으. & \pm & त్లి \\
\hline 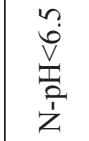 & \&̊. & $\hat{o}$ & s. & à & $\stackrel{n}{o}$ & $\begin{array}{l}n \\
\alpha \\
o\end{array}$ & $\begin{array}{l}0 \\
0 \\
0 \\
\end{array}$ & 尚 & $\hat{\alpha}$ & $\hat{a}$ & ô. & $\stackrel{0}{\circ}$ \\
\hline 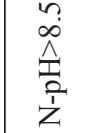 & $\begin{array}{l}\infty \\
0 \\
0\end{array}$ & $\hat{a}$ & ठे & $\hat{a}$ & ڤे & $\begin{array}{l}\infty \\
0 \\
0\end{array}$ & $\begin{array}{l}\infty \\
0 \\
0 \\
0\end{array}$ & $\begin{array}{l}\infty \\
\stackrel{0}{0} \\
0\end{array}$ & $\begin{array}{l}0 \\
0 \\
0\end{array}$ & $\begin{array}{l}0 \\
0 \\
0\end{array}$ & $\hat{a}$ & $\hat{a}$ \\
\hline : & $\stackrel{ }{r}$ & $\stackrel{\text { fo }}{r}$ & $\underset{\infty}{\widetilde{\infty}}$ & $\stackrel{\text { ㄱ. }}{r}$ & $\begin{array}{l}\hat{a} \\
\infty \\
\infty\end{array}$ & $\stackrel{n}{\Omega}$ & 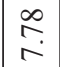 & \begin{tabular}{|l|}
0 \\
$\infty$ \\
\end{tabular} & 文 & $\stackrel{\widehat{y}}{r}$ & 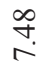 & $\sqrt[n]{n}$ \\
\hline مै & $\begin{array}{l}\infty \\
\infty \\
0\end{array}$ & तิ & $\begin{array}{l}\bar{\infty} \\
0 \\
0\end{array}$ & $\begin{array}{c}\infty \\
\infty \\
0\end{array}$ & ô. & 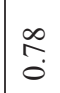 & $\begin{array}{c}\infty \\
\infty \\
0\end{array}$ & $\begin{array}{l}R \\
0 \\
0\end{array}$ & $\begin{array}{c}+ \\
\infty \\
0 \\
0\end{array}$ & \begin{tabular}{|l|}
$\infty$ \\
$\infty$ \\
0 \\
0
\end{tabular} & $\begin{array}{l}n \\
\infty \\
0 \\
0\end{array}$ & $\begin{array}{c}\hat{\infty} \\
0 \\
0\end{array}$ \\
\hline$\stackrel{n}{\theta}$ & $\overrightarrow{\mathrm{d}}$ & ๙ิ & $\stackrel{\bullet}{\sim}$ & $\stackrel{\substack{a \\
\sim}}{\infty}$ & ñ & $\begin{array}{l}\infty \\
\infty \\
-1\end{array}$ & $\stackrel{\infty}{\sim}$ & $\cong$ & 呇 & $\underset{m}{8}$ & $\stackrel{8}{\sim}$ & $\underset{\sim}{\infty}$ \\
\hline O & $\hat{0}$ & $\stackrel{\infty}{\underset{c}{-}}$ & $\stackrel{\circ}{\circ}$ & $\stackrel{0}{0}$ & \&. & $\begin{array}{l}\stackrel{2}{0} \\
0\end{array}$ & $\begin{array}{l}0 \\
2 \\
0\end{array}$ & $\begin{array}{l}0 \\
0 \\
0\end{array}$ & $\begin{array}{l}0 \\
0 \\
0\end{array}$ & $\begin{array}{l}0 \\
0 \\
0\end{array}$ & $\stackrel{\circ}{0}$ & $\stackrel{\text { o }}{.}$ \\
\hline 仓 & $\begin{array}{l}8 \\
\dot{\pi}\end{array}$ & $\stackrel{8}{\circ}$ & $\underset{i}{8}$ & $\begin{array}{l}8 \\
\text { in }\end{array}$ & $\begin{array}{l}8 \\
0 \\
\end{array}$ & $\begin{array}{l}8 \\
i \\
i\end{array}$ & $\begin{array}{l}8 \\
i \\
i\end{array}$ & $\begin{array}{l}8 \\
\text { in }\end{array}$ & $\begin{array}{l}8 \\
i \\
i\end{array}$ & $\begin{array}{l}8 \\
\text { in }\end{array}$ & $\underset{i}{8}$ & $\begin{array}{l}8 \\
\dot{i}\end{array}$ \\
\hline 竟 & nุ? & $\begin{array}{l}n \\
\infty \\
i\end{array}$ & $\stackrel{\text { ¿े }}{\text { i }}$ & $\stackrel{n}{a}$ & $\begin{array}{l}\text { İ } \\
\text { î. }\end{array}$ & 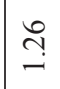 & $\begin{array}{l}0 \\
\stackrel{2}{-} \\
-\end{array}$ & 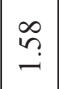 & $\underset{\sigma}{\sigma}$ & $\stackrel{?}{\stackrel{0}{+}}$ & in & $\stackrel{ \pm}{m}$ \\
\hline 胥 & 8 & 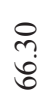 & ๙ે & 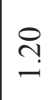 & 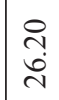 & in & $\begin{array}{l}q \\
\dot{q} \\
m\end{array}$ & 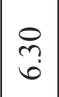 & $\stackrel{\bigcirc}{=}$ & $\begin{array}{l}\dot{8} \\
\dot{+} \\
+\end{array}$ & $\stackrel{\circ}{6}$ & 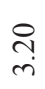 \\
\hline 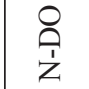 & @. & $\bar{\sigma}$ & $\delta$ & $\begin{array}{l}\infty \\
\infty \\
0\end{array}$ & 占 & $\begin{array}{l}+ \\
\infty \\
0 \\
0\end{array}$ & $\begin{array}{c} \pm \\
\vdots \\
0 \\
0\end{array}$ & $\begin{array}{l}\infty \\
0 \\
0\end{array}$ & $\begin{array}{l}0 \\
\infty \\
0\end{array}$ & $\mid \begin{array}{l}\infty \\
\infty \\
0\end{array}$ & $\begin{array}{l}+ \\
\stackrel{0}{0}\end{array}$ & $\begin{array}{l}\infty \\
\infty \\
0\end{array}$ \\
\hline 롬 & $\stackrel{t}{a}$ & fे. & $\stackrel{\circ}{\circ}$ & $\stackrel{\infty}{\stackrel{\infty}{\longrightarrow}}$ & $\begin{array}{l}0 \\
\stackrel{2}{2} \\
\end{array}$ & $\begin{array}{l}\stackrel{0}{N} \\
ٍ ِ\end{array}$ & $\begin{array}{l}\vec{a} \\
\stackrel{i}{I}\end{array}$ & $\mid \begin{array}{c}\tilde{O} \\
\dot{I}\end{array}$ & $\overrightarrow{\vec{d}}$ & $\begin{array}{l}n \\
o \\
\varrho\end{array}$ & $\tilde{\Omega}$ & $\stackrel{\Delta}{=}$ \\
\hline 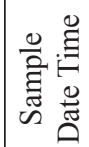 & 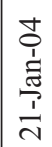 & 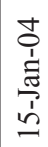 & 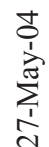 & 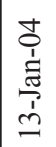 & 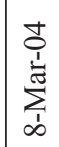 & 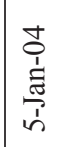 & $\begin{array}{l}t \\
0 \\
1 \\
1 \\
0 \\
1 \\
\dot{1} \\
d\end{array}$ & 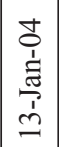 & 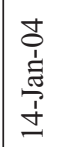 & 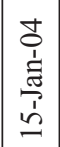 & 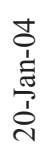 & 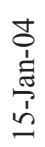 \\
\hline 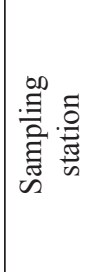 & 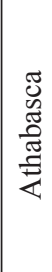 & 总 & 蒿 & $\begin{array}{l}3 \\
0 \\
0 \\
\overline{1}\end{array}$ & 茎 & 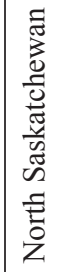 & 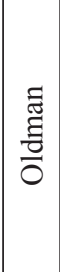 & 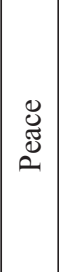 & 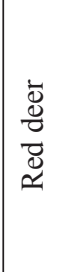 & $\begin{array}{l}\vec{\partial} \\
0 \\
\tilde{y} \\
\text { क }\end{array}$ & 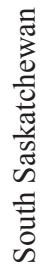 & 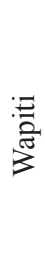 \\
\hline$\dot{s} \dot{z}$ & - & $N$ & $m$ & $\nabla$ & in & 0 & $r$ & $\infty$ & $a$ & $\circ$ & $=$ & $\simeq$ \\
\hline
\end{tabular}

For total exceedance dominant parameters were used whereas in mean exceedance all the parameters were used.

(iii) This model was applied to obtain the mean exceedance level for water quality parameters of the clusters in all the rivers of study area.

(iv) Charts were developed to present parameter exceedance patterns in clusters.

\section{Results and Discussions}

In these subsequent paragraphs, we discussed about the (i) development of normalization models; (ii) Principal Component Analysis; (iii) cluster development for water quality classification; (iv) clusters comparison with CWQI classes; (v) mean exceedance of parameters for rivers; (vi) treatment decision making using outputs of mean exceedance model; and (vii) treatment technologies for exceeded parameters.

\section{Development of Normalization Model}

In first step, the normalization model was developed using Eq. 1 and Eq. 2 [13]. Both these equations were applied for all 17 parameters on each site of all 12 rivers. The results of selected river sampling sites for the selected dominant parameters are shown in Table 3. Formulae were applied on the original values of parameters to get the normalized values.

\section{Principal Component Analysis}

The results of Principal Component Analysis led to seven major principal components with variability of about $89 \%$. From these identified PCs, it was found that PC-1 was the indicator of watershed geology, PC-2, PC-3, and PC-4 were the indicators of mineralization (natural and anthropogenic) and $\mathrm{PC}-3$, PC-5, and PC-7 were the indicators of LULC activities. The dominant parameters which were discovered from seven PCs were TUR, TDS, pH, DO, FC, Fe and TC [13].

\section{Cluster Development for Water Quality Classification}

The developed model given in Eq. 3 was used to calculate the total exceedence values for the normalized data of dominant parameters. Five clusters for water quality classification were developed and evaluated using these exceedence values. Clusters shown in Fig. 2 are presenting the maximum, minimum and the mean exceedence values of the dominant parameters.

From Fig. 2, it is clear that minimum, maximum and mean exceedence increases with increase in cluster number. It means that the water quality deteriorates from cluster 1 to cluster 5 respectively [13]. 


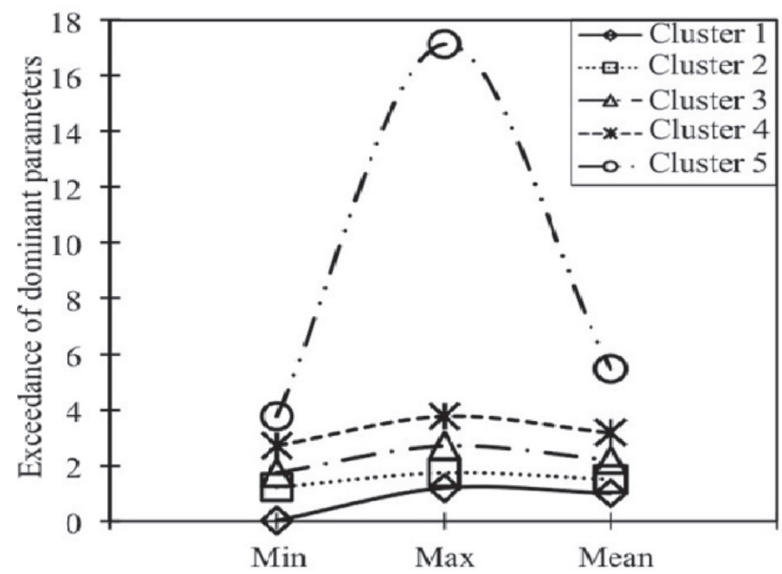

Fig. 2. Patterns of five clusters produced from minimum, maximum and mean of the exceedance values of dominant parameters [13].

\section{Clusters Comparison with CWQI Classes}

As discussed, the clusters obtained, were compared with CWQI classes as shown in Fig. 3. The quantitative evaluation showed very close match of clusters with CWQI classes. The results revealed that for clusters $1,2,3,4$ and 5 cumulative agreement for 0 deviation were $85.71 \%, 83.54 \%, 90.22 \%, 80.74 \%$ and $83.40 \%$ respectively. For \pm 1 deviation the agreement percentages were $14.29 \%, 16.46 \%, 8.83 \%$, $19.26 \%$ and $16.60 \%$ respectively. For \pm 2 deviation, the percentage of agreement was $1.40 \%$ in cluster 3 . The percentages of agreement showed very strong match between clusters and CWQI classes which indicates the suitability and worth of cluster based classification system for the surface water quality of Alberta Rivers [13].

\section{Mean Exceedance of Parameters for Rivers}

Table 4 indicates the list of the parameters playing their roles in water quality. The model provided the identification of parameters which were exceeded and which were not exceeded in each cluster of river. The numerical values also indicated the levels of exceedance for each exceeded parameter. The mean exceedence of fecal coliforms and turbidity is higher in almost all the rivers which indicates that water quality in Alberta river is deteriorated mostly due to their precence. The increase in FC is related to increasing anthropogenic activities [13]. The turbidity in water quality could be related to snow melting and precipitation. The run off from different types of LULC increase the sediment levels in the surface waters, which increase TUR. Although all the parmeters listed are responsible for degrading the water quality but greater values of TP and $\mathrm{Mn}$ in Battle River and involvement of higher values of $\mathrm{Mn}$ and $\mathrm{Fe}$ in Milk river indicate their major roles in detoriating the water quality of these rivers. It shows increase in natural mineralization also affected the water quality. The details about the mean exceedance of parameters of the twelve rivers in Alberta are given in subsequent paragraphs.

\section{Athabasca River}

For Athabasca River, the mean exceedance for the parameters is given in Table 4. The mean exceedance for FC was above: (i) 1 for cluster 3 and cluster 4; (ii) 2 for cluster 5. The mean exceedance for TUR was above: (i) 0.40 for cluster 3; (ii) 1 for cluster 4, (iii) 2 for cluster 5 . For cluster 5, the mean exceedance for (i) TP was above 0.30; (ii) TC and DOC was above 0.20; (iii) Fe was above 0.10 . For cluster 4 , the mean exceedance for: (i) $\mathrm{Fe}$ was above 0.20; (ii) TP, TC and DOC was above 0.10 . For cluster 3 , the mean exceedance for: TP,

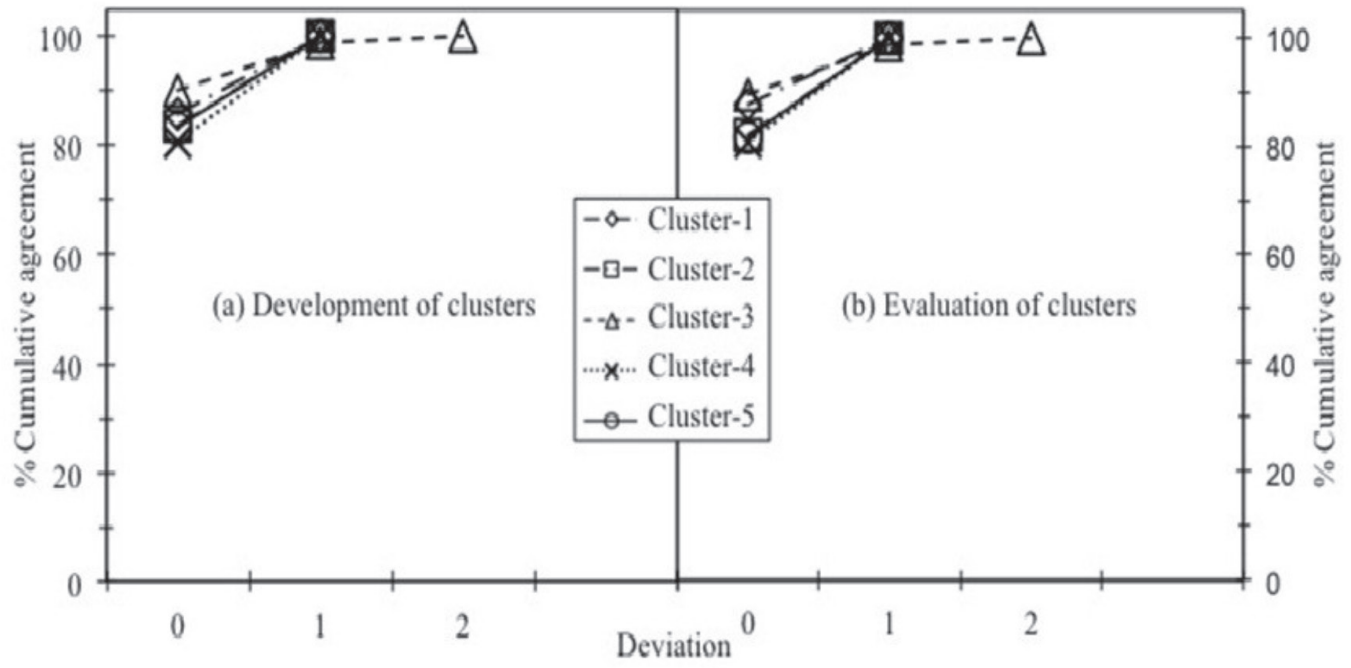

Fig. 3. Percentage cumulative agreement between clusters and CWQI classes based on deviations for (a) development of clusters and (b) evaluation of clusters [13]. 
TC, and DOC was above 0.10. Overall the parameters with the higher mean exceedance values were $\mathrm{FC}$ and TUR. The snow melting and precipitation from the different types of land LULC increase the sediment levels in the surface waters, which increase TUR. The sources of deterioration in Athabasca River are also the surface runoff from the different LULC types including broad leaf forests, needle leaf forests and cereal crops/ grasses [13]. A study accomplished for Athabasca River, found that the contamination could be related to LULC related runoff from the forestry and agricultural activities [24]. The lowest to highest exceedance were observed from cluster 3 towards cluster 5 .

\section{Battle River}

The mean exceedance for the parameters of Battle River is given in Table 4. The mean exceedance for FC was above: (i) 1 for cluster 3; (ii) 2 for cluster 4 and cluster 5 . The mean exceedance for TUR was above: (i) 0.50 for cluster 3; (ii) 0.80 for cluster 4 and (iii) 1 for cluster 5. The mean exceedance for Mn was above: (i) 0.10 for cluster 3; (ii) 0.40 for cluster 4; (iii) 1 for cluster 5 . The mean exceedance for DO was above: (i) 0.20 for cluster 4 ; and (ii) 0.60 for cluster 5 . The mean exceedance for TP was above: (i) 0.20 for cluster 3; (ii) 0.30 for cluster 4 ; and (iii) 0.50 for cluster 5 . The mean exceedance for DOC was above: (i) 0.20 for cluster 3; (ii) 0.30 for cluster 4 ; and (iii) 0.40 for cluster 5 . The mean exceedance for TC was above: (i) 0.20 for cluster 3; (ii) 0.10 for cluster 4 ; and (iii) 0.20 for cluster 5 . The mean exceedance for TN was above: (i) 0.20 for cluster 4 and cluster 5 . We also observed mean exceedance over 0.10 for TDS and Fe in cluster 5. The parameters, which showed higher mean exceedance as compared to others parameters, were FC, TUR, Mn, DO, and TP. The range of mean exceedance for these parameters was from: (i) 0.28 to 1.77 in cluster 3 ; (ii) 0.38 to 2 in cluster 4; and (iii) 0.58 to 2.97 in cluster 5 . Battle river is dominated by cereal crops and grasses. The corrosion in water might be related to the agriculture activities. The natural and anthropogenic activities are also responsible for deteriorating its condition [25].

\section{Bow River}

For Bow River, the mean exceedance for the parameters is given in Table 4. The lowest to highest exceedance for the parameters were observed from cluster 1 towards cluster 5 . The mean exceedance for FC was above: (i) 1 for cluster 1, cluster 2 and cluster 3; (ii) 2 for cluster 4; and (iii) 3 for cluster 5 . The mean exceedance for TUR was above: (i) 0.2 for cluster 2; (ii) 0.4 for cluster 3; (iii) 0.5 for cluster 4 ; and (iv) 1 for cluster 5 . The mean exceedance for TP was above: (i) 0.1 for cluster 3 and cluster 4; and (ii) 0.3 for cluster 5. Fe also showed exceedance of about 0.30 in cluster 4. FC and TN showed exceedance in all five clusters. FC, TUR and TP showed higher exceedance in cluster 3, cluster 4 and cluster 5 . The cluster results showed that water quality of Bow River in BOR-2, BOR-3 and BOR-4 weakened as compared to BOR1 during the growing season. This could be related to the agricultural activities of cereal crops as these three sites are located near agricultural areas whereas BOR-1 is located near needle leaf forest. The increase in TUR in Bow River could also be the result of snow melting period [25].

\section{Elbow River}

For Elbow River, the lowest to highest exceedance for the parameters were observed from cluster 2 towards cluster 5 (See Table 4). The mean exceedance for FC was above: (i) 1 for cluster 2; (ii) 2 for cluster 3 and cluster 4; and (iii) 4 for cluster 5. The mean exceedance for TUR was above: (i) 0.05 for cluster 2; (ii) 0.10 for cluster 3; (iii) 0.3 for cluster 4 ; and (iv) 0.5 for cluster 5. TP, TC and TN showed exceedance above 0.10 for cluster 5 . The most prominent parameters in terms of exceedance were FC and TUR. Cluster 5 showed exceedance in six parameters (i.e., FC, TUR, $\mathrm{TP}, \mathrm{TC}, \mathrm{TN}$ and DOC). Cluster 4 had exceedance in three parameters (i.e., FC, TUR and TN). Cluster 2 and cluster 3 showed exceedance only in FC and TUR. Water quality of Elbow River might be deteriorated mostly because of runoff from agriculture and residential development [26].

\section{Milk River}

The mean exceedance of parameters for the clusters of Milk River is given in Table 4. The exceedance values for the exceeded parameters are higher for cluster 5 as compared to cluster 4 . The mean exceedance for: (i) FC and $\mathrm{Fe}$ was above 2; (ii) Mn and TUR was above 1. TP, DOC, TC, TN, and TDS had mean exceedance above 0.10 in cluster 5 . The parameters in the order from the highest to lowest mean exceedance were $\mathrm{Mn}, \mathrm{FC}$, Fe, TUR, TDS and DO respectively in cluster 4 . The mean exceedance for $\mathrm{Mn}, \mathrm{FC}$ and Fe were above 1 . The parameters of Cluster 5 for Milk River from the highest to lowest values were: FC, Fe, Mn, TUR, TP, DOC, TC, TN, TDS, pH and DO. Milk River is surrounded by the cereal crops/grasses and the snow melting period around this river was before 5-April-08. Agricultural activities and surface runoff due to snow melting could be the reason of the deteriorated water quality of Milk River during growing season. The mineralization in Milk River due to $\mathrm{Mn}$ and Fe could be a major factor for the deteriorated water quality throughout the year [27].

\section{North Saskatchewan River}

The mean exceedance of parameters for the clusters of North Saskatchewan River is given in Table 4. The lowest to highest exceedance for the parameters were 


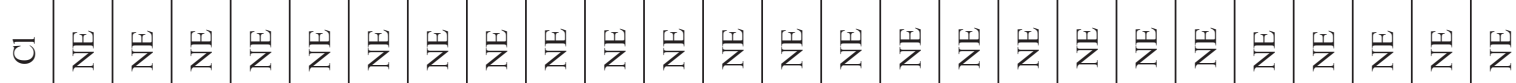

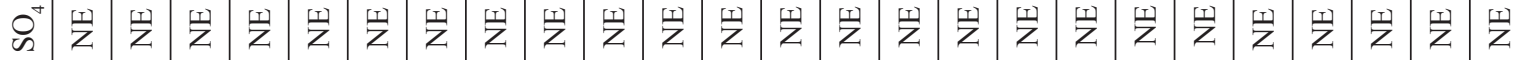

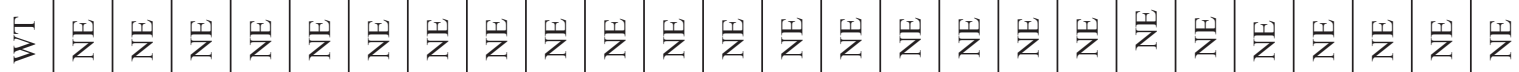

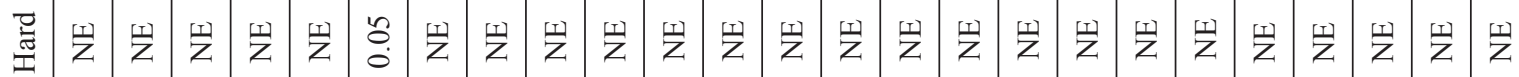

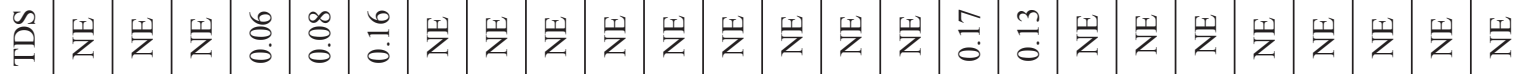

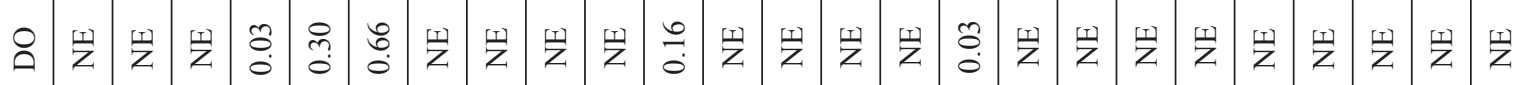

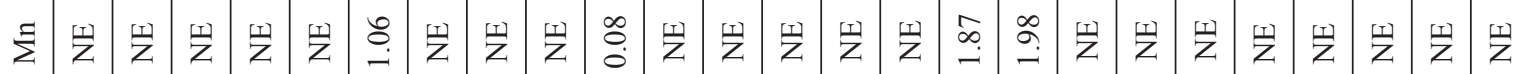

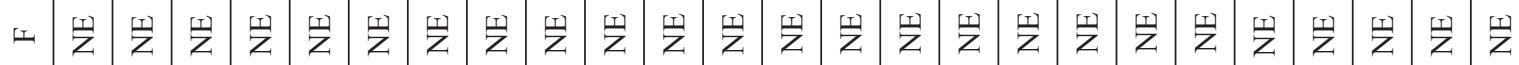

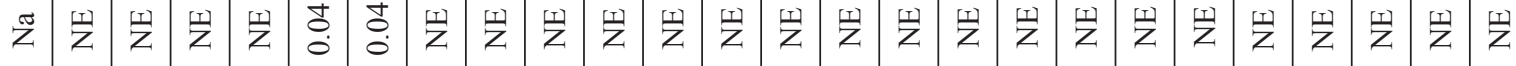

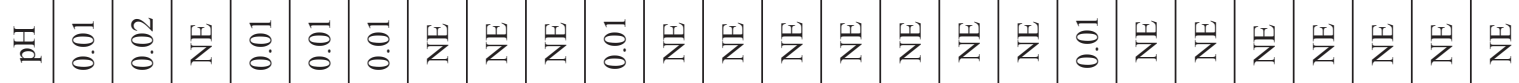
Z资 证 总

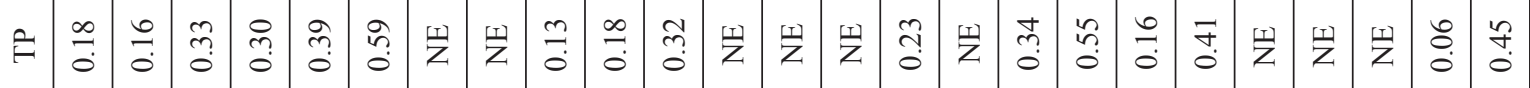

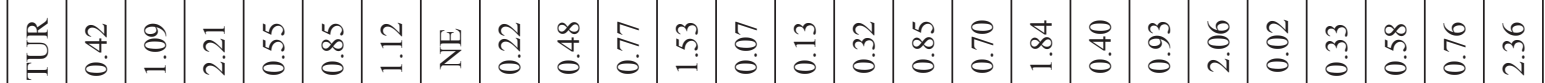

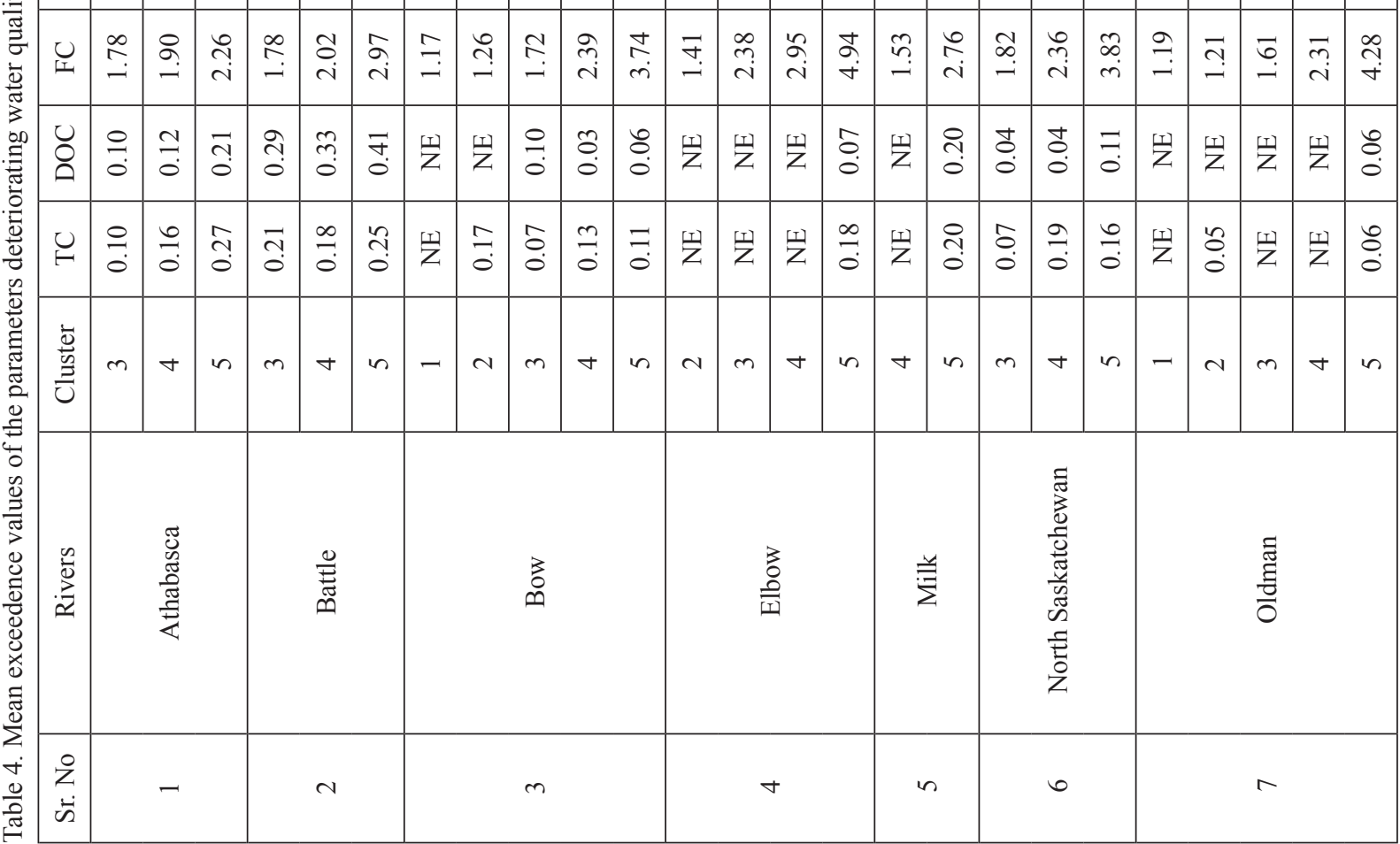




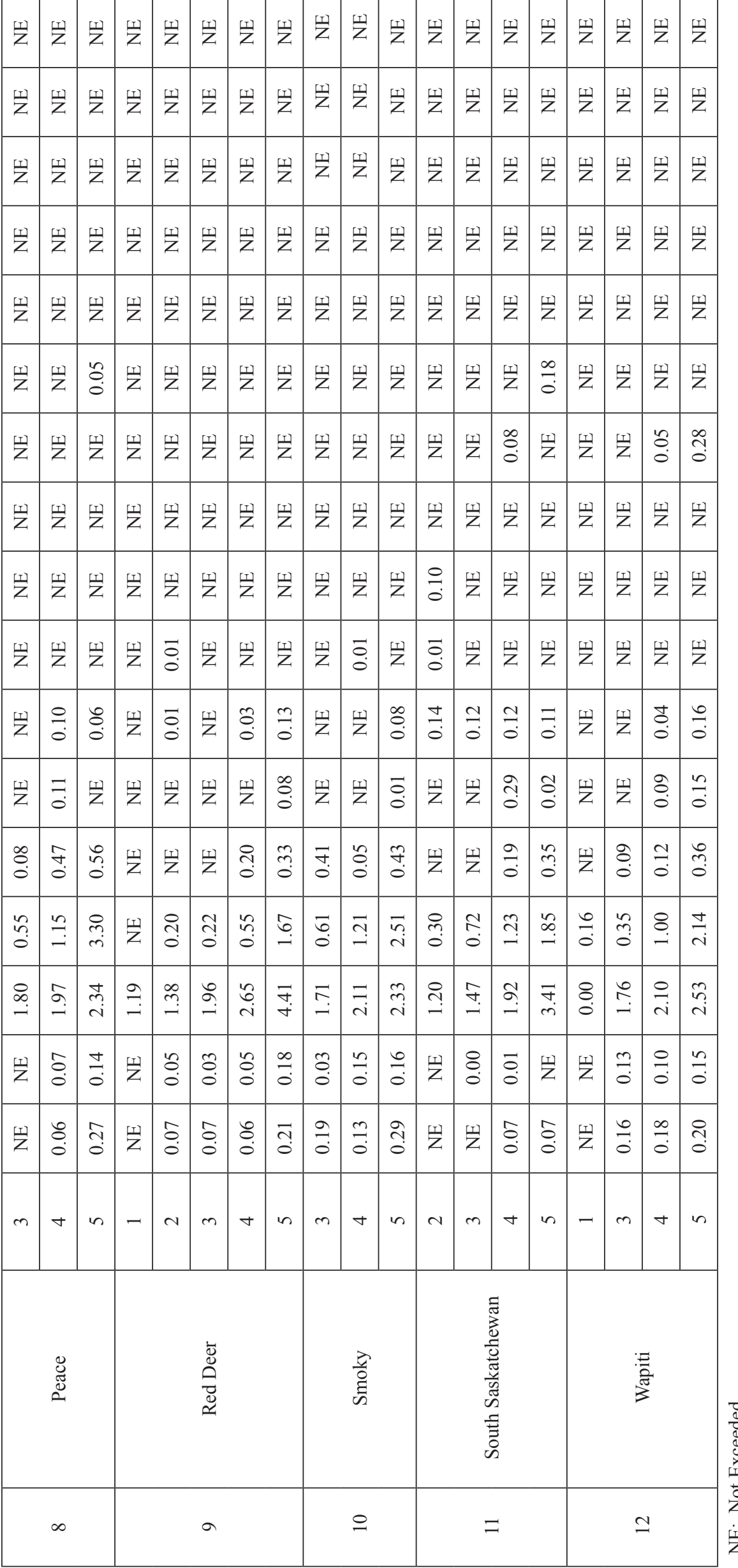


observed from cluster 3 towards cluster 5. The mean exceedance for FC was above: (i) 1 for cluster 1; (ii) 2 for cluster 4; and (iii) 3 for cluster 5. The mean exceedance for TUR was above: (i) 2 for cluster 5; (ii) 0.5 for cluster 4 ; and (iii) 0.3 for cluster 3 . The mean exceedance was above 0.1 for TP, TC, DOC and TN for cluster 5. TP and TC had the exceedance above 0.1 . TP in cluster 1 showed exceedance above 0.50 and TN had exceedance above 0.1. The mean exceedance was higher for FC, TUR, TP and TC as compared to other parameters for North Saskatchewan River. A major portion of North Saskatchewan River is surrounded by cereal crops/grasses on downstream side of the river and by needle leaf and broad leaf forests at upstream side. Worsened water quality of North Saskatchewan River in growing season could be due to agriculture activities. The variation of clusters in different months during the period 2004-2008 was associated with the snow melting. The probable sources of contamination for the North Saskatchewan River could be the pollutants which are carried by snowmelt from the activities related to agriculture and forestry [28].

\section{Oldman River}

The mean exceedance of parameters for the clusters of Oldman River is given in Table 4. The lowest to highest exceedance for the parameters were observed from cluster 1 towards cluster 5 . The mean exceedance for FC was above: (i) 1 for cluster 1, cluster 2 and cluster 3; (ii) 2 for cluster 4; and (iii) 4 for cluster 5. The mean exceedance for TUR was above: (i) 0.30 for cluster 2; (ii) 0.50 for cluster 3; (iii) 0.70 for cluster 4 ; and (iv) 2 for cluster 5. The mean exceedance was above: (i) 0.40 for TP; and (ii) 0.10 for TN. The exceedance was above 0.10 for FE in cluster 4 . The parameters with higher exceedance in: (i) cluster 5 was FC, TUR, TP, and TN; (ii) cluster 4 was FC, TUR and Fe; (iii) cluster 2 and cluster 3 were FC and TUR; and (iv) cluster 1 was FC. The Oldman river water quality is flagging becaue of the anthropogenic activities like recreation, forestry, agriculture activities and oil and gas development [29]. The naturally happening process of sulfide oxidation in Oldman River Basin was detected because of the wide network of drainage and irrigation canals [30].

\section{Peace River}

The mean exceedance of parameters for the clusters of Peace River is given in Table 4. The mean exceedance from the lowest to highest range was observed from cluster 3 towards cluster 5 . The mean exceedance for TUR was above: (i) 0.50 for cluster 3; (ii) 1 for cluster 4; and (iii) 3 for cluster 5 . The mean exceedance for FC was above: (i) 1 for cluster 3, cluster 4 and (ii) 2 for cluster 5. For cluster 5, the exceedance for: (i) TP was above 0.50 ; (ii) TC was above 0.20 ; (iii) DOC was above 0.10 . The mean exceedance for TP was above 0.40 for cluster 4 and it was above 0.10 for TN. The parameters with the higher mean exceedance were TUR, FC, and TP in all three clusters. As river is surrounded by crops, broad leaves and needle leaves forest and most of Peace River is in the snow melting period of 6-Apr-08 to 15-May-08, therefore agriculture activities and increase in contamination due to snow melting could be the reason for detoriation in water quality [13].

\section{Red Deer River}

The mean exceedance of parameters for the clusters of Red Deer River is given in Table 4. The mean exceedance from the lowest to the highest range was observed from cluster 1 towards cluster 5 . The mean exceedance for FC was above: (i) 1 for cluster 1, cluster 2 and cluster 3; and (ii) 4 for cluster 4 . The mean exceedance for TUR was above: (i) 0.20 for cluster 2, cluster 3; (ii) 0.50 for cluster 4; (iii) 1 for cluster 5 . For cluster 5: (i) TP was above 0.30; (ii) TC was above 0.20; (iii) $\mathrm{DOC}$ and $\mathrm{TN}$ was above 0.10 . TP was above 0.10 for cluster 4 . The parameters with the highest mean exceedance were: (i) FC, TUR, and TP in cluster 4 and cluster 5; (ii) FC, TUR, and TC in cluster 2 and cluster 3 . FC was the only exceeded parameter in cluster 1 . In growing season contaminaion in water quality of red deer River could be associated with the agriculture activities as river is surrounded by cereal crops and grasses and run off due to snow melting [25].

\section{Smoky River}

The mean exceedances of parameters for the clusters of Smoky River are shown in Table 4. The mean exceedance from the lowest to highest range was observed from cluster 3 towards cluster 5 . The mean exceedance for TUR was above: (i) 0.50 for cluster 3; (ii) 1 for cluster 4; (iii) 2 for cluster 5. The mean exceedance for FC was above: (i) 1 for cluster 3; (ii) 2 for cluster 4 and cluster 5 . For cluster 5 , the exceedance was above: (i) 0.40 for TP; (ii) 0.20 for TC; and (iii) 0.10 for DOC. TC and DOC had exceedance above 0.10 in cluster 4. TP was above 0.40 in cluster 3 and TC was above 0.10 for cluster 3 . The parameters with the highest mean exceedance were: (i) FC, TUR, and TP in cluster 3 and cluster 5; (ii) FC, TUR, and TC in cluster 2 and cluster 3. FC was the only parameter in cluster 1. The parameters with the highest mean exceedance were: (i) FC, TUR, and TP in cluster 3 and cluster 5; (ii) FC and TUR in cluster 2 and cluster 3 . The weakening in the water quality of Smoky River could be related to of discharges from oil sands refinery and runoff from the forest and agricultural activities [25].

\section{South Saskatchewan River}

The mean exceedance of parameters for the clusters of South Saskatchewan River is shown in Table 4. The mean exceedance from the lowest to highest 


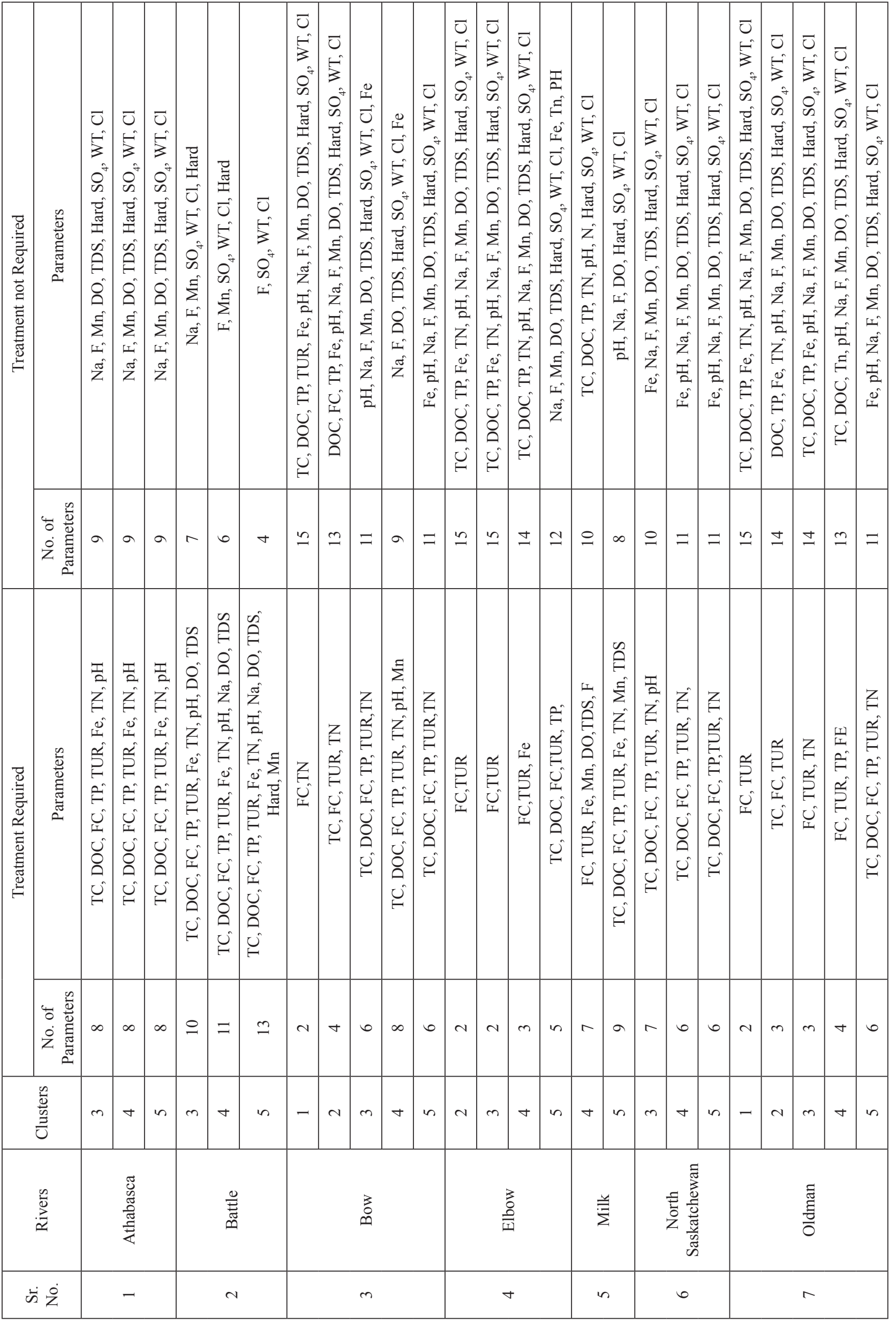




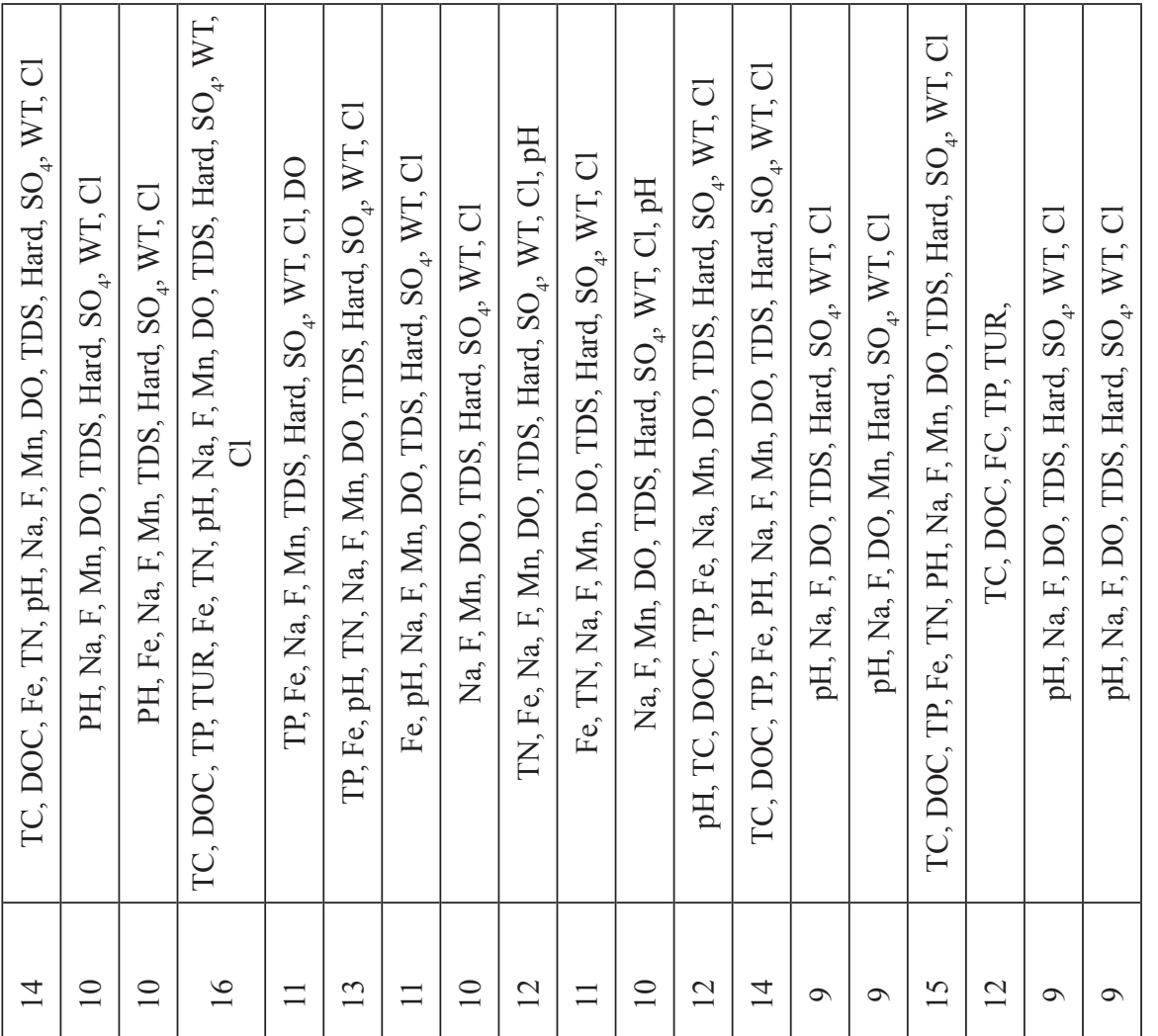

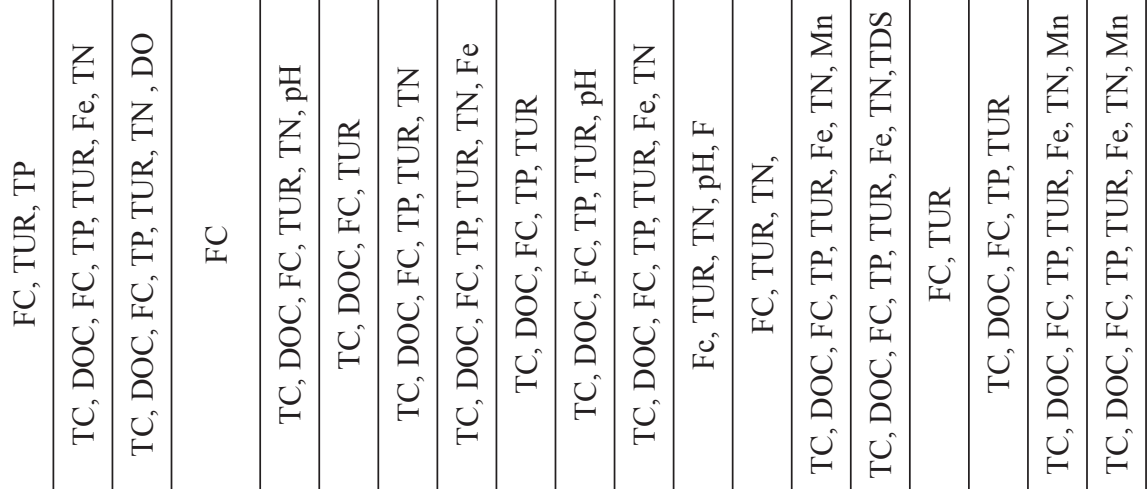

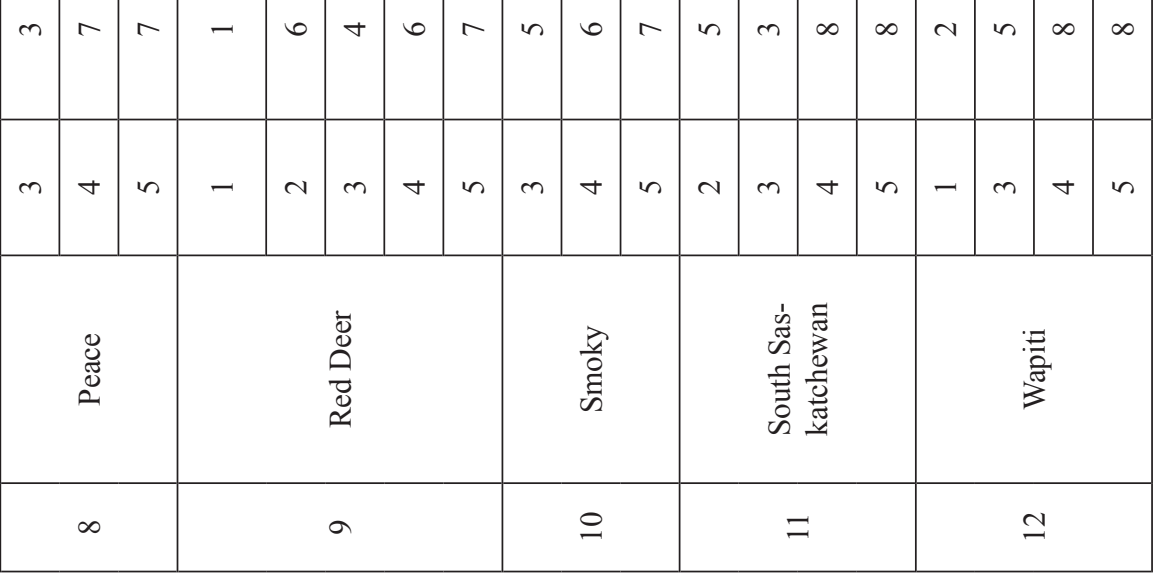


range was observed from cluster 2 towards cluster 5 . The mean exceedance for FC was above: (i) 1 for cluster 2 , cluster 3, and cluster 4; (ii) 3 for cluster 5 . The mean exceedance for TUR was above: (i) 0.30 for cluster 2 ; (ii) 0.70 for cluster 3 ; (iii) 1 for cluster 4 and cluster 5. The exceedance was above 0.30 for TP and it was more than 0.10 for DO and TN. For cluster 4, the mean exceedance for $\mathrm{Fe}$ was above 0.20 and it was above 0.10 for TN and TP. TN was also found above 0.10 for both cluster 2 and cluster 3 . The parameters with the highest mean exceedance were: (i) FC, TUR, and TN in cluster 2 and cluster 3; (ii) FC, TUR and Fe in cluster 4; and (iii) FC, TUR and TP in cluster 5. The intense agricultural activities found in South Saskatchewan River Basin could be responsible for contamination and inclusion of sediments and nutrients in the water thus deteriorating its quality [25].

\section{Wapiti River}

The mean exceedance of parameters for the clusters of Wapiti River is given in Table 4. The mean exceedance from the lowest to highest range was observed from cluster 1 towards cluster 5 . The mean exceedance for FC was above: (i) 1 for cluster 3; (ii) 2 for cluster 4 and cluster 5 . The mean exceedance for TUR was above: (i) 0.10 for cluster 1; (ii) 0.30 for cluster 3; (iii) 1 for cluster 4; and (iv) 2 for cluster 5 . For cluster 5, the mean exceedance for: (i) TP was above 0.30 ; (ii) $\mathrm{Mn}$ was above 0.20 ; (iii) $\mathrm{TC}, \mathrm{TN}, \mathrm{Fe}$ and DOC was above 0.10 . The mean exceedance for TP, TC and DOC was above 0.10 in cluster 4. The exceedance for TC and DOC was above 0.10 for cluster 3. The parameters with the highest mean exceedance were: (i) TUR in cluster 1; (ii) FC and TUR in cluster 2; (iii) FC, TUR and TC in cluster 4; and (iv) FC, TUR, and TC in cluster 5. The anthropogenic sources might be responsible for deteriorating the water quality of Wapiti River which include discharge of sewage effluent from pulp mill and municipalities [31].

\section{Treatment Decision Making Using Outputs of Mean Exceedance Model}

Clusters of Alberta River water and outputs of the mean exceedance model might guide us in making the decisions regarding the targeted treatment technologies required for certain parameters by the rivers. The parameters with exceedance, specifies that the water quality is deteriorated thus needs treatment technology for those parameters. The parameters whose mean exceedance values are not exceeded, represents that water is not contaminated because of these parameters and therefore advance level of expensive and ineffective treatment technologies are not needed in such places. Table 5 is showing the decision of treatment that was made using the outputs of mean exceedance model. It shows that based on the outputs of mean exceedance model, different clusters of all major rivers need different treatment technologies. Thus the treatment technologies for the parameters which are not exceeded, are not needed to be implemented. We can see that cluster 3, 4 and 5 of Athabasca River needs treatment for 8 out of 17 parameters only. Similarly cluster 3, 4 and 5 of Battle River needs treatment for 10, 11 and 13 parameters. We can also deduce that cluster 5 of Battle river is contaminated with highest number of parameters thus needs treatment for all 13 parameters. In Elbow River, cluster 2 and 3 needs treatment for FC and TUR only whereas cluster 4 needs treatment for FC, TUR and Fe. Cluster 1 of Red Deer River only needs to be treated for a single parameter i.e FC. The details of the rest of the clusters for all the rivers and treatment required or not required for different parameters, are enlisted in Table 5.

The economic development in many developed countries including Canada, exponential growth in human population, climate change, caused serious threats to natural ecosystems [15]. The industrial zones release many water pollutants in fresh water bodies. These pollutants have very long-lasting effects on the sustainability of local ecosystems [7]. The industrial wastewaters contain many toxic inorganic and organic compounds like PCB, PAH, VOCs, etc. which can cause damage to delicate aquatic ecosystems [7]. The water pollution of rivers not only affects the environmental sustainability but also caused economic burden through its impacts on human health due to the dependency of potable water on rivers in many parts of the world [32]. It was reported [11] that lakes are more prone to be disturbed by water pollutants. To address various water pollutants, water quality assessment or its modelling is highly desirable. After knowing water quality, the suitable treatment of water or wastewater is necessary [33].

The present study reported the use of exceedance model to identify the parameters which exceeded the Canadian drinking water quality guidelines and obtained the exceedance patterns of water quality parameters in clusters of 12 major rivers of Alberta during the period of five years. The results suggested that the pattern of exceedance paramters varied according to spatial patterns of water bodies. The use of such exceedance models are very handy to decide what treatment strategy should be adopted at a particular place. The current study suggested the specific water quality parameters along their patterns of exceedance level which needed treatment. The source of water pollution was also identified where a specific treatment was needed. The use of probability to illustrate water quality is applied in studies [34-38]. The various exceedance models were used for finding exceedance water quality parameters to decide some useful water management strategies around the world [35-38]. 


\section{Conclusions}

In this study, a mean exceedance model was developed for surface water quality parameters. The model was applied to identify the parameters which were exceeded the guidelines and contributed towards the deterioration of surface water quality in different clusters of 12 major rivers in Alberta. It provided information on the parameters which were not exceeded in these clusters. It indicated the exceedance patterns of parameters in clusters. The outputs of model was utilized for decision making on treatment of parameters in each cluster.The parameters with higher mean exceedance were: (i) FC and TUR for Athabasca River; (ii) FC, TUR, Mn, DO and TP for Battle River; (iii) FC, TUR and TP for Bow River; (iv) FC and TUR for Elbow River; (v) FC, Fe, Mn and TUR for Milk River; (vi) FC, TUR, TP and TC for North Saskatchewan River; (vii) FC, TUR, TP, TN, and Fe for Oldman River; (viii) TUR, FC, and TP for Peace River; (ix) FC, TUR, TP and TC for Red Deer River; (x) FC, TUR, and TP for Smoky River; (xi) FC, TUR, TN and TP for South Saskatchewan River; and (xii) FC, TUR and TC for Wapiti River. The mean exceedance was highest for FC and TUR in all the rivers and these were also dominant parameters. From the results of treatment decision making, it was found that the higher numbers of parameters required treatment in cluster 4 and cluster 5 for six rivers which include: (i) Athabasca; (ii) Battle; (iii) Milk; (iv) Peace; (v) South Saskatchewan; and (vi) Wapiti. The exceedance modelling was useful in: (i) identifying the parameters exceeded above the water quality guidelines in each cluster; (ii) obtaining the patterns of exceedance for the exceeded parameters; (iii) obtaining the exceedance level for each parameter of a cluster; (iv) targeting the parameters for the specific treatment on the basis of exceedance level; (v) identifying the source of water pollution; and (vi) deciding the targeted treatment technology.

\section{Acknowledgments}

We acknowledge the Natural Sciences and Engineering Research Council of Canada (NSERC) for providing "Postgraduate Scholarship at Doctoral Level" to Tahir Ali Akbar and Alberta Environment for providing water quality data. We also acknowledge the support of COMSATS University Islamabad, Abbottabad Campus, Pakistan for providing facilities for completing this research work.

\section{Conflict of Interest}

The authors declare no conflict of interest.

\section{References}

1. KÜKRER S., MUTLU E. Assessment of surface water quality using water quality index and multivariate statistical analyses in Saraydüzü Dam Lake, Turkey. Environ. Monit. Assess., 191 (2), 71, 2019.

2. The Water Chronicles. Guide to Canada's Drinking Water. The Water Chronicles, Ottawa, ON, Canada, 2008.

3. BOYD, C.E. Water Quality: An Introduction, 2nd ed.; Springer International Publishing: Cham, Switzerland, 2015.

4. MEYER A.M., KLEIN C., FÜNFROCKEN E., KAUTENBURGER R., BECK H.P. Real-time monitoring of water quality to identify pollution pathways in small and middle scale rivers. Sci. Total Environ., 651, 2333, 2019.

5. LUOMA S., OKKONEN J. Impacts of future climate change and Baltic sea level rise on groundwater recharge, groundwater levels, and surface leakage in the Hanko aquifer in Southern Finland. Water, 6 (12), 3671, 2014.

6. OCKENDEN M.C., DEASY C.E., BENSKIN C.M.W.H., BEVEN K.J., BURKE S., COLLINS A.L., EVANS R., FALLOON P.D., FORBER K.J., HISCOCK K.M., HOLLAWAY M.J., KAHNA R., MACLEOD C.J.A., REANEY S.M., SNELL M.A., VILLAMIZAR M.L., WEARING C., WITHERS P.J.A., ZHOU J.G., HAYGARTH P.M. Changing climate and nutrient transfers: Evidence from high temporal resolution concentration-flow dynamics in headwater catchments. Sci. Total Environ., 548, 339, 2016.

7. MAHMOOD Q., SHAHEEN S., BILAL M., ZEB B.S., TARIQ M., ULLAH Z., ALI A. Chemical pollutants from industrial estate Pakistan-A threat to environmental sustainability App. Water Sci., 9 (3), 47, 2019.

8. TYAGI S., SHARMA B., SINGH P., DOBHAL R. Water quality assessment in terms of water quality index. Am. J. Water Resour., 1, 38, 2013.

9. TSAKIRIS G., ALEXAKIS D. Water quality models: An overview. Eur. Water 37, 46, 2012.

10. ZHANG L., THOMAS S., MITSCH W.J. Design of realtime and long-term hydrologic and water quality wetland monitoring stations in South Florida, USA. Ecol. Eng., 108, 455, 2017.

11. DALAKOTI H., MISHRA S., CHAUDHARY M., SINGAL S. K. Appraisal of water quality in the lakes of Nainital District through numerical indices and multivariate statistics, India. Int. J. River Bas. Manage., 16, 11, 2017.

12. ALTENBURGER R., AIT-AISSA S., ANTCZAK P., BACKHAUS T., BARCELÓ, D., SEILER T.B., BRION F., BUSCH W., CHIPMAN K., DE ALDA M.L., et al. Future water quality monitoring-Adapting tools to deal with mixtures of pollutants in water resource management. Sci. Total Environ., 512, 551, 2015.

13. AKBAR T.A., HASSAN Q.K., ACHARI G. Clusterization of surface water quality and its relation to climate and land use/cover. JEP, 4 (4), 333, 2013.

14. KAZAKIS N., CHALIKAKIS K., MAZZILLI N., OLLIVIER C., MANAKOS A., VOUDOURIS K. Management and research strategies of karst aquifers in Greece: Literature overview and exemplification based on hydrodynamic modeling and vulnerability assessment of a strategic karst aquifer. Sci. Total Environ. 643, 609, 2018. 
15. MAHMOOD Q., PERVEZ A., ZEB B.S., ZAFFAR H., YAQOOB H., WASEEM M., ZAHIDULLAH, AFSHEEN S. Natural treatment systems as sustainable ecotechnologies for the developing countries, Biomed. Resear. Int., 2013, 19, 2013.

16. https://www.safewater.org/fact-sheets-1/2017/1/23/ultrafiltr ationnanoandro, (accessed on $23^{\text {rd }}$ February 2020).

17. COLLIVIGNARELli M.C., ABBÀ A., BENIGNA I., SORLINI S., TORRETTA V. Overview of the main disinfection processes for wastewater and drinking water treatment plants, Sustainability, 10, 86, 2018.

18. WILCZAK A., JACANGELO J.G., MARCINKO J.P., ODELL L. H., KIRMEYER G. J., WOLFE R. L. Occurrence of nitrification in chloraminated distribution systems. J. Am. Water Works Assoc., 88 (7), 74, 1996.

19. DOWNING D.J., PETTAPIECE W.W. Natural regions and subregions Alberta, Natural Regions Committee, Government of Alberta, AB, Canada, 2006.

20. National Aeronautics and Space Administration (NASA). MODIS/Terra land cover type yearly L3 global $1 \mathrm{~km}$ SIN Grid V004, land cover product, MOD12Q1, LP DAAC User services, U.S. Geological Survey, Center for Earth Resources Observation and Science, Sioux Falls, SD, USA, 2004.

21. Alberta Environment and Sustainable Resource Development. Alberta River water quality index: Objectives. Water Data, Government of Alberta, Canada, 2015.

22. Health Canada. Guidelines for Canadian drinking water quality. Federal-Provincial-Territorial Committee on Drinking Water of the Federal-Provincial-Territorial Committee on Health and the Environment, Ottawa, ON, Canada, 2019.

23. Ministry of the Environment. Technical support document for Ontario drinking water standards, objectives and guidelines. Government of Ontario, Toronto, ON, Canada, 2006.

24. WRONA F.J., CAREY J., BROWNLEE B. Contaminant sources, distribution and fate in the Athabasca, Peace and Slave River Basins, Canada. J. Aquat. Ecosyst. Stress Recovery, 8 (1), 39. 2000.

25. AKBAR T.A. Development and application of water quality classification models. Unpublished doctoral dissertation, University of Calgary, Canada. 2013.

26. SOSIAK A., DIXON J. Impacts on water quality in the upper Elbow River. Water Sci. Technol, 53 (10), 309, 2006.

27. ANDERSON A.M. River water quality of Battle river. Water Sciences Branch, Water Management Division, Natural Resources Service, Alberta Environment, Canada, 1999.
28. MITCHELL P. Water quality of the North Saskatchewan river in Alberta. Surface Water Assessment Branch, Technical Services and Monitoring Division, Alberta Environmental Protection, Canada, 1994.

29. KONING C.W., SAFFRAN K. A., LITTLE J. L., FENT L. Water quality: The basis for watershed management in the Oldman River Basin, Canada. Water Sci. Technol., 53 (10), 153, 2006.

30. DO H.T., LO S.L., CHIUEH P.T., PHANTHI L.A. Design of sampling locations for mountainous river monitoring. Environ. Model. Softw., 27, 70, 2012.

31. SCRIMGEOUR G.J., PATRICIA A. CHAMBERS P.A. Cumulative effects of pulp mill and municipal effluents on epilithic biomass and nutrient limitation in a large northern river ecosystem, Canadian Can. J. Fish. Aquat. 57(7), 1354, 2011.

32. JABEEN S., MAHMOOD Q., NAWAB B. High Economic Impacts of poor water and sanitation in various communities in Pakistan (An Environmental Economic Perspective), Cent. Asian J. Environ. Sci.Technol. Innov., $1,60,2020$.

33. GULZAR F., MAHMOOD Q., BHATTI Z.A., ZEB B.S., SHAHEENS., HAYAT T., SHAHID N., ZEB T. Industrial wastewater treatment in internal circulation bioreactor followed by wetlands containing emergent plants and algae, World J. Microbiol. Biotechnol., 34 (8), 119, 2018.

34. CHEN C-F., TSAIL.-Y., CHI-HSUAN FAN C.-H., LIN J.-Y. Using exceedance probability to determine total maximum daily loads for reservoir water quality management. Water, 8 (11), 541, 2016.

35. CHEN C.F., SHENG M.Y., CHANG C.L., KANG S.F., LIN J.Y. Application of the SUSTAIN model to a watershedscale case for water quality management. Water 6, 3589, 2014.

36. PRADHAN N.R., DOWNER C.W., JOHNSON B.E. A physics based hydrologic modeling approach to simulate non-point source pollution for the purposes of calculating TDMLs and designing abatement measures. In Practical Aspects of computational chemistry III; Springer: New York, NY, USA, 249, 2014.

37. YANG G., BEST E.P.H. Spatial optimization of watershed management practices for nitrogen load reduction using a modeling-optimization framework. J. Environ. Manag., 161, 260, 2015.

38. ZHOU F., DONG Y., WU J., ZHENG J., ZHAO Y. An indirect simulation-optimization model for determining optimal TMDL allocation under uncertainty. Water, 7 (11), 6650, 2015. 
